\title{
Clinical Advantages Including Medication Adherence with Conversion to Once-Daily Advagraf and Sirolimus Combination in Stable Kidney Recipients
}

\section{Cheol Woong Jung*}

Korea University Anam Hospital, 73, Inchon-ro, Seongbuk-gu, Seoul 02841, Korea

Keywords: Immunology; Creatinine; Blood

\section{Introduction}

With advances in transplantation immunology and immunosuppressant, long-term outcomes had improved in kidney transplantation [1]. However, for the past decades, the long-term results of renal allograft have not changed [2]. The long-term use of a calcineurin-inhibitor (CNI) and medication non-adherence are important factors that can affect the long-term results $[3,4]$. Therefore, decreasing exposure of CNI and the adherence of patients to their respective immunosuppressant regimens have become more significant. Medications for kidney recipients are very complicated, and the dosage often changes and many patients often forget to take their medicine. Medication non-adherence can cause graft failure in transplant recipients who are required to go on long-term medication use [4]. Following tacrolimus, Advagraf (Astellas Pharma Inc., Tokyo, Japan) was developed to facilitate the formulation to use once daily. In comparison to the twice-daily formulation, Advagraf is expected to improve medical adherence [5]. Sirolimus is also once-daily formulation and has been used to minimize calcineurin-inhibitor (CNI) exposure. A reduction in the CNI showed improved renal function, improved allograft survival, and decreased allograft rejection [3].

The purpose of this study is the analysis of the clinical advantages of once-daily Advagraf and sirolimus combination by decreasing the use of CNI and improving medication adherence in stable kidney recipients.

\section{Materials and Methods}

The present study is approved by the investigation review Committee of the Korea University Anam Hospital (NO. ED13060). Thirty-four kidney transplant (KT) recipients with stable renal function (more than 6 months after KT, 24-hour urine protein $<400 \mathrm{mg}$, creatinine variance $<30 \%$ within 3 months) underwent a conversion from a tacrolimus-mycophenolate mofetil (MMF) - based regimen to a once-daily Advagraf-sirolimus regimen at Korea University Anam Hospital from September 2011 to March 2013. The starting dosage of Advagraf was equivalent to the tacrolimus dosage before conversion. The patients were followed up right after the conversion and every two months after the conversion. The target trough level (C0) of Advagraf was $2-4 \mathrm{ng} / \mathrm{mL}$ and the target of sirolimus was $6-10 \mathrm{ng} / \mathrm{mL}$.

Thirty-four patients who underwent a conversion to a once-daily Advagraft and sirolimus combination were retrospectively reviewed at 3,12 and 24 months. The patients' renal function including serum creatinine and glomerular filtration rate (GFR), lipid profile including total cholesterol, low density lipoprotein (LDL) cholesterol and triglyceride, complete blood count, electrolyte including potassium, urine analysis including proteinuria and pyuria, fast glucose and mean arterial pressure (MAP) were reviewed from medical records (Table 1).

A medication adherence questionnaire including pre-conversion,
12 months and 24 months was filled out at 12 and 24 months after the conversion using the Morisky-Green Test (MGT) [6]. Participants answered the questions with the help of transplantation coordination nurses on the basis of recent memory in a month. The questionnaire of pre-conversion was filled at 12 months. From the questionnaire of each patient, the numbers of positive responses were counted in the times of pre-conversion, 12 months and 24 months. In MGT, low adherence was defined as more than 3 positive responses in the questions including oblivion of medication, confused medication time, the voluntary discontinuance in good condition and the voluntary discontinuance in poor condition (Table 2). Adherence improvement was defined to reduce the numbers of positive responses in MGT.

All statistical analyses were performed with SPSS version 17.0 (SPSS Inc., Chicago, Ill, United States) by using the $\chi 2$ test for categorical variables and the $t$ test for continuous variables. Results were reported as mean \pm standard deviation (SD) or numbers (percentage of total). The $p$ value of less than 0.05 was considered statistically significant. The data of 3,12 and 24 months compared with the baseline data of preconversion.

\section{Results}

Among 40 kidney recipients who underwent a conversion from a tacrolimus-mycophenolate mofetil (MMF) - based regimen to a oncedaily Advagraf-sirolimus regimen at Korea University Anam Hospital from September 2011 to March 2013, 6 recipients were excluded including 2 due to worsened DM, 2 due to recurrent urinary tract infections, 1 due to aggravated proteinuria and 1 to dyslipidemia.

The mean age of the 34 patients was $43.05 \pm 9.92$ years $(52.9 \%$ male). The transplants from living donor were 16 (47.05\%). The mean time from transplantation to the conversion to Advagraf and sirolimus was $28.8 \pm 15.0$ months. The mean Advagraf level at 3 months after conversion was $3.00 \pm 0.51 \mathrm{ng} / \mathrm{mL}$. The mean sirolimus level was 6.64 $\pm 2.01 \mathrm{ng} / \mathrm{mL}$. Mean Advagraf dose was $2.56 \pm 1.24 \mathrm{mg}$ and mean sirolimus dose was $1.74 \pm 0.50 \mathrm{mg}$ (Table 3).

Patients who converted to the Advagraf and sirolimus regimen showed a slight improvement in renal function 3 months after the

*Corresponding author: Cheol Woong Jung, Korea University Anam Hospital 73, Inchon-ro, Seongbuk-gu, Seoul 02841, Korea, Tel: 82-10-4576-5677; E-mail: midasia@naver.com

Received August 03, 2015; Accepted August 24, 2015; Published August 27 2015

Citation: Jung CW (2015) Clinical Advantages Including Medication Adherence with Conversion to Once-Daily Advagraf and Sirolimus Combination in Stable Kidney Recipients. Pharm Anal Acta 6: 407. doi:10.4172/21532435.1000407

Copyright: (C) 2015 Jung CW. This is an open-access article distributed under the terms of the Creative Commons Attribution License, which permits unrestricted use, distribution, and reproduction in any medium, provided the original author and source are credited. 
conversion, as evidenced by creatinine levels $(\mathrm{p}=0.024)$ and eGFR $(\mathrm{p}<0.001)$; however, the difference was insignificant after 12 months. Additionally, lipid profiles including total cholesterol, LDL cholesterol, and triglycerides deteriorated further in most patients at every time point $(3,12$, and 24 months). Serum fast glucose level and proteinuria increased significantly at 12 months $(\mathrm{p}=0.016, \mathrm{p}=0.030$, respectively). MAP decreased significantly at 12 and 24 months $(\mathrm{p}<0.001, \mathrm{p}<0.001$, respectively) (Table 2, Figure 1). Mean numbers of hypertension medications decreased over time without statistical significance $(0.62$ \pm 0.75 at pre-conversion, $0.62 \pm 0.75$ at 3 months, $0.50 \pm 0.67$ at 12 months, $0.43 \pm 0.61$ at 24 months).

Adverse effects after the conversion included gastrointestinal trouble ( 8 patients, $23.5 \%$ ), oral ulcers ( 3 patients, $8.8 \%$ ), and peripheral edema (4 patients, 11.7\%). Graft rejection, morbidity, and mortality did not occur within the study period.

The medication adherence questionnaire was filled out at 12 and 24 months by 30 recipients. In the MGT for medication adherence, after 12 months from conversion, the adherent groups without positive responses was $83.33 \%$ and the moderate adherent groups with 1 or 2 positive responses was $16.66 \%$. After 24 months, the adherent was $76.66 \%$ and the moderate adherent group was $23.33 \%$. There were adherence improvements of $23.33 \%$ after 12 months and $16.66 \%$ after 24 months, compared to pre-conversion (Table 4).

\section{Discussion}

The minimization of $\mathrm{CNI}$ is recommended and proposed due to the fact that long-term CNI toxicity eventually leads to chronic allograft nephropathy. As a result of intrarenal vasoconstriction and progressive fibrosis, nephrotoxicity is the most important adverse effect that may occur due to $\mathrm{CNI}[7,8]$. As an important example of CNI minimization, specific inhibitors of the mammalian target of rapamycin (mTOR) reduce renal graft dysfunction by reducing interstitial fibrosis and tubular atrophy [9]. Tacrolimus and mTOR inhibitors have similar structures and bind to FK506 binding proteins [7]. The synergic effect between tacrolimus and mTOR inhibitors can be expected to decrease calcineurin-inhibitor (CNI) administration, which, in turn, decreases chronic CNI toxicity and improves graft survival $[10,11]$. In this study, renal function after the conversion to sirolimus improved at 3 months but did not improve after 12 months. Similar to this study, the Spare-
the-Nephron trial reported the renal function after conversion from CNI to sirolimus improved at 1 year, but did not change significantly at 2 years [12]. Long-term follow up studies are necessary.

The advantages of mTOR inhibitor are its viral suppression [3], antitumor effect [13], and the cardiovascular benefits from the reduction of the neointimal hyperplasia of the vessel [14]. CNI is known to lead to hypertension because of oxidative stress, sympathetic activation, and renal affrent vasoconstriction, which have been shown in several studies [15]. In contrast, Zeider et al. suggested that mTOR inhibitors may reduce the incidence of hypertension, although the data are not clear [15]. Interestingly, this study also showed MAP decreased after 12 months from conversion. Randomized controlled trials are needed to further explain the interesting findings. Studies have reported that the adverse effects of mTOR inhibitors are wound complications, lymphoceles, dyslipidemia, oral ulcer, proteinuria, and diabetes [1618]. Similarly, in this study, all lipid profiles, including total cholesterol, LDL cholesterol, and triglycerides increased significantly at every time.

The studies on medical adherence initially were conducted in patients with hypertension. It was reported that low medication adherence in hypertension treatment is the main cause of the failure to control blood pressure $[19,20]$. Various tests have been used to assess medication adherence, such as a medication event monitoring system, self-reporting, collateral reporting, capsule counts, laboratory tests for metabolites of pharmaceuticals, and questionnaires [21]. The MGT [6] from various questionnaires is now used most frequently and has been the gold standard for blood pressure control, especially in the U.S [22]. MGT is simple and easy to answer, as it only contains 4 questions (Table 3).

In the field of transplantation, medication adherence is very important. Non-adherence to prescribed medical regimens has been proven to be associated with a risk of acute rejection and allograft failure in renal transplant recipients [23]. Schmid-Mohler et al. reported that medication non-adherence contributed $16.3-36.4 \%$ to graft losses and $19.9 \%$ to late acute rejection after kidney transplantation [24]. Although there are differences in reporting or criteria, the prevalence rates of non-adherence were reported to be between 23 and 35\% [25,26]. In this study, the prevalence rates of non-adherence, including the moderate and low adherence groups, were reported to be $40.00 \%$ at the pre-conversion, $16.66 \%$ at 12 months and $23.33 \%$ at 24 months after

\begin{tabular}{|c|c|c|c|c|}
\hline & Pre-conversion & 3 months & 12 months & 24 months \\
\hline Serum Creatinine (mg/dL) & $1.14 \pm 0.33$ & $1.09 \pm 0.30^{*}$ & $1.11 \pm 0.37$ & $1.13 \pm 0.34$ \\
\hline eGFR $\left(\mathrm{mL} / \mathrm{min} / 1.73 \mathrm{~m}^{2}\right)$ & $67.59 \pm 14.87$ & $72.33 \pm 15.16^{*}$ & $70.59 \pm 15.36$ & $68.14 \pm 14.56$ \\
\hline Total cholesterol (mg/dL) & $152.31 \pm 27.58$ & $184.19 \pm 28.86^{\star}$ & $178.11 \pm 19.18^{*}$ & $176.74 \pm 24.56^{*}$ \\
\hline LDL cholesterol (mg/dL) & $70.83 \pm 19.55$ & $91.14 \pm 22.52^{*}$ & $101.08 \pm 21.41^{*}$ & $107.31 \pm 17.74^{*}$ \\
\hline Triglyceride (mg/dL) & $107.50 \pm 40.22$ & $147.86 \pm 69.43^{*}$ & $151.33 \pm 67.22^{*}$ & $153.22 \pm 73.86^{*}$ \\
\hline Hemoglobin (g/dL) & $13.46 \pm 1.61$ & $13.21 \pm 1.70$ & $13.42 \pm 1.45$ & $13.36 \pm 1.44$ \\
\hline WBC $\left(x 10^{3} / \mu \mathrm{L}\right)$ & $7.94 \pm 2.08$ & $7.20 \pm 1.80^{\star}$ & $7.49 \pm 1.96$ & $7.70 \pm 2.21$ \\
\hline Platelet count $\left(\times 10^{3} / \mu \mathrm{L}\right)$ & $214.92 \mathrm{~K} \pm 54.77$ & $212.56 \mathrm{~K} \pm 56.13$ & $205.06 \mathrm{~K} \pm 55.28$ & $212.40 \mathrm{~K} \pm 54.00$ \\
\hline Potasium (mmol/L) & $4.24 \pm 0.47$ & $4.14 \pm 0.46$ & $4.13 \pm 0.44$ & $4.30 \pm 0.61$ \\
\hline Phosphate (mg/dL) & $3.08 \pm 0.57$ & $2.99 \pm 0.59$ & $2.96 \pm 0.50$ & $3.04 \pm 0.60$ \\
\hline Fast glucose (mg/dl) & $91.89 \pm 10.75$ & $93.89 \pm 9.83$ & $97.67 \pm 15.46^{*}$ & $95.97 \pm 14.21$ \\
\hline Proteinuria & $+0.14 \pm 0.35$ & $+0.36 \pm 0.54$ & $+0.36 \pm 0.49^{*}$ & $+0.20 \pm 0.40$ \\
\hline Pyuria & $+0.61 \pm 1.18$ & $+0.56 \pm 1.03$ & $+0.50 \pm 1.19$ & $+0.71 \pm 1.38$ \\
\hline MAP $(\mathrm{mmHg})$ & $97.74 \pm 7.76$ & $96.65 \pm 11.93$ & $90.35 \pm 10.41^{*}$ & $89.66 \pm 10.04^{*}$ \\
\hline
\end{tabular}

GFR, glomerular filtration rate; LDL, low density lipoprotein; WBC, white blood cell; MAP, mean arterial pressure

All data are expressed as mean \pm SD.

${ }^{*} \mathrm{P}<0.05$

The data of 3,12 and 24 months compared with the baseline data of pre-conversion in $\mathrm{P}$ value.

Table 1: Mean clinical outcomes on the conversion from tacrolimus based regimen to once-daily Advagraf-sirolimus regimen after 3,12 and 24 months. 
Citation: Jung CW (2015) Clinical Advantages Including Medication Adherence with Conversion to Once-Daily Advagraf and Sirolimus Combination in Stable Kidney Recipients. Pharm Anal Acta 6: 407. doi:10.4172/21532435.1000407

1. Do you ever forget to take medications?

2. Are you careless at times about taking medicine?

3. When you feel well, do you stop taking the medication?

4. If you feel unwell, do you stop taking the medication?

Table 2: Morisky-Green Test (MGT)

\begin{tabular}{|l|l|}
\hline Characteristics & Total $(\mathbf{n}=\mathbf{3 4})$ \\
\hline Age, mean $\pm \mathrm{SD}$, years & $43.05 \pm 9.92$ \\
\hline Male gender, No (\%) & $18(52.95 \%)$ \\
\hline Transplant from living donor & $16(47.05 \%)$ \\
\hline Mean Conversion day after KT, months & $29.8 \pm 15.0$ \\
\hline Mean follow up, months & $28.0 \pm 4.41$ \\
\hline Advagraf dose†, mean $\pm \mathrm{SD}, \mathrm{mg}$ & $2.56 \pm 1.24$ \\
\hline Advagraf level†, mean $\pm \mathrm{SD}, \mathrm{ng} / \mathrm{mL}$ & $3.00 \pm 0.51$ \\
\hline Sirolimus dose†, mean $\pm \mathrm{SD}, \mathrm{mg}$ & $1.74 \pm 0.50$ \\
\hline Sirolimus level $\dagger$, mean $\pm \mathrm{SD}, \mathrm{ng} / \mathrm{mL}$ & $6.64 \pm 2.01$ \\
\hline
\end{tabular}

All data are expressed as mean $\pm \mathrm{SD}$

†The dose and level of the drugs were measured at 3 months after conversion.

Table 3: The patient's demographics, mean doses and levels of the Advagraf and sirolimus.

\begin{tabular}{|l|l|l|l|}
\hline & Pre-conversion & 12 months & 24 months \\
\hline $\begin{array}{l}\text { Adherent (no positive responses) } \\
\begin{array}{l}\text { Moderate Adherence (1 positive } \\
\text { responses) }\end{array}\end{array}$ & $18(60.00)$ & $25(83.33)$ & $23(76.66)$ \\
\hline $\begin{array}{l}\text { Moderate Adherence (2 positive } \\
\text { responses) }\end{array}$ & $4(13.33)$ & $2(6.66)$ & $2(6.66)$ \\
\hline Low Adherence (3 positive responses) & $0(0)$ & $0(0)$ & $0(0)$ \\
\hline Low Adherence (4 positive responses) & $0(0)$ & $0(0)$ & $0(0)$ \\
\hline
\end{tabular}

Data are expressed as numbers (\%).

Table 4: The results of medical adherence with Morisky-Green Test at preconversion, 12 months and 24 months.
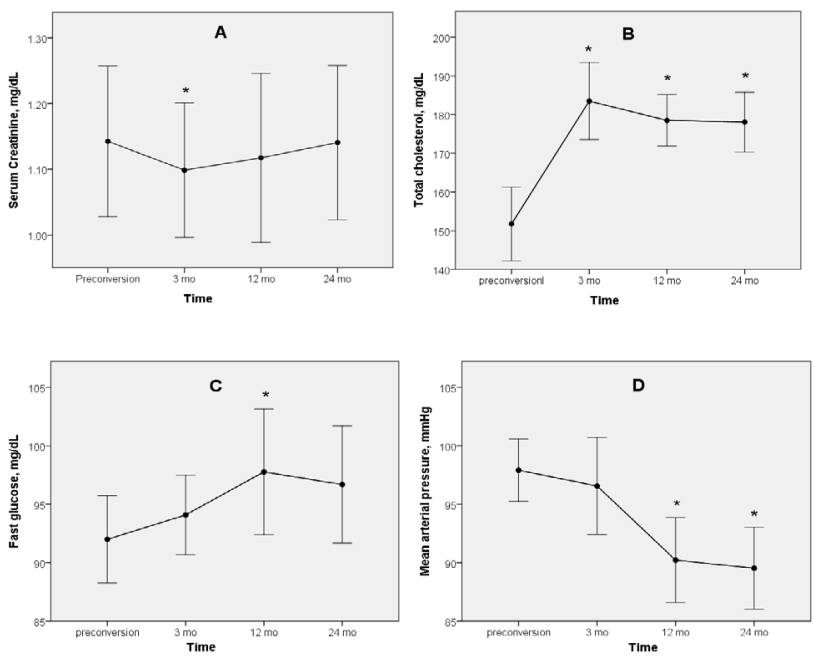

Figure 1: Changes in serum creatinine, total cholesterol, serum fast glucose and mean arterial pressure during 2-year follow-up after conversion to once-daily Advagraf and sirolimus combination in stable kidney recipients. (A) Serum creatinine decreased at 3 month. (B) Total cholesterol increased during 2-year follow-up. (C) Serum fast glucose increased at 1 year. (D) Mean arterial pressure decreased after 1 year. ${ }^{*} \mathrm{P}<0.05$ conversion. It is clear that lower dose frequencies play an important role in improving medical adherence and long-term graft outcomes [27]. In this sense, the once-daily Advagraf and sirolimus combination may play an important role in improving medical adherence.

Following medical adherence and graft function, cost effectiveness is also important for recipients who are required to use immunosuppressants for a long time. In the transplantation clinic, changes in recipients' economic statuses may have a significant influence on medication adherence. In the data gathered from the National Health Service in the UK over 10 years, it was reported that sirolimus was the most economical in all scenarios [28]. Recently, it was reported that once-daily Advagraf would be more effective both in terms of cost and medical adherence [29]. In this center, immediately before the conversion, the mean daily dose of tacrolimus and MMF was $3.20 \pm 1.40 \mathrm{mg}$ and $1 \mathrm{~g}$. At 3 months after the conversion, the mean daily dose of Advagraf and sirolimus was $2.56 \pm 1.24 \mathrm{mg}$ and $1.74 \pm$ $0.50 \mathrm{mg}$ (Table 1). Based on the cost of immunosuppressants widely in Korea, the mean daily cost of tacrolimus and MMF was $28.95 \pm 12.66$ USD and Advagraf and sirolimus was $25.86 \pm 9.26$ USD. Over time, the difference between the two combinations will become larger due to the reduction in dose of Advagraf with sirolimus. Cost effectiveness is an important factor in choosing immunosuppressants and large-scale research is essential and required.

\section{Conclusion}

For kidney recipients who will be required to take immunosuppressants for a long time, medication adherence is an important factor in maintaining graft function. The once-daily Advagraf and sirolimus combination can be a safe and effective regimen in stable kidney recipients, as the study shows that renal function maintained stable and medication adherence was improved with controllable adverse effects.

\section{References}

1. Hariharan S, Johnson CP, Bresnahan BA, Taranto SE, McIntosh MJ, et al. (2000) Improved graft survival after renal transplantation in the United States, 1988 to 1996. N Engl J Med 342: 605-612.

2. Matas AJ, Smith JM, Skeans MA, Thompson B, Gustafson SK, et al. (2014) OPTN/SRTR 2012 Annual Data Report: kidney. Am J Transplant 14 Suppl 1: $11-44$

3. Ekberg H, Tedesco-Silva H, Demirbas A, VÃtko S, Nashan B, et al. (2007) Reduced exposure to calcineurin inhibitors in renal transplantation. $\mathrm{N}$ Engl J Med 357: 2562-2575.

4. Kahan BD, Welsh M, Urbauer DL, Mosheim MB, Beusterien KM, et al. (2000) Low intraindividual variability of cyclosporin $A$ exposure reduces chronic rejection incidence and health care costs. J Am Soc Nephrol 11: 1122-1131.

5. Wu SW, Tsai HC, Tsai PY, Hung TW, Chang HR, et al. (2013) Conversion to prolonged release tacrolimus formulation in stable kidney transplant recipients. Swiss Med Wkly 143: w13850.

6. Morisky DE, Green LW, Levine DM (1986) Concurrent and predictive validity of a self-reported measure of medication adherence. Med Care 24: 67-74.

7. Perry I, Neuberger J (2005) Immunosuppression: towards a logical approach in liver transplantation. Clin Exp Immunol 139: 2-10.

8. Burdmann EA, Andoh TF, Yu L, Bennett WM (2003) Cyclosporine nephrotoxicity. Semin Nephrol 23: 465-476.

9. Stallone G, Infante B, Schena A, Battaglia M, Ditonno P, et al. (2005) Rapamycin for treatment of chronic allograft nephropathy in renal transplant patients. J Am Soc Nephrol 16: 3755-3762.

10. Vu MD, Qi S, Xu D, Wu J, Fitzsimmons WE, et al. (1997) Tacrolimus (FK506) and sirolimus (rapamycin) in combination are not antagonistic but produce extended graft survival in cardiac transplantation in the rat. Transplantation 64 
Citation: Jung CW (2015) Clinical Advantages Including Medication Adherence with Conversion to Once-Daily Advagraf and Sirolimus Combination in Stable Kidney Recipients. Pharm Anal Acta 6: 407. doi:10.4172/21532435.1000407

1853-1856.

11. De Simone P, Nevens F, De Carlis L, Metselaar HJ, Beckebaum S, et al. (2012) Everolimus with reduced tacrolimus improves renal function in de novo liver transplant recipients: a randomized controlled trial. Am J Transplant 12: 30083020 .

12. Weir MR, Mulgaonkar S, Chan L, Shidban H, Waid TH, et al. (2011) Mycophenolate mofetil-based immunosuppression with sirolimus in renal transplantation: a randomized, controlled Spare-the-Nephron trial. Kidney Int 79: 897-907.

13. Lieberthal W, Levine JS (2009) The role of the mammalian target of rapamycin (mTOR) in renal disease. J Am Soc Nephrol 20: 2493-2502.

14. Paoletti E, Amidone M, Cassottana P, Gherzi M, Marsano L, et al. (2008) Effect of sirolimus on left ventricular hypertrophy in kidney transplant recipients: a 1-year nonrandomized controlled trial. Am J Kidney Dis 52: 324-330.

15. Zeier M, Van Der Giet M (2011) Calcineurin inhibitor sparing regimens using m-target of rapamycin inhibitors: an opportunity to improve cardiovascular risk following kidney transplantation. Transpl Int 24: 30-42.

16. Pengel LH, Liu LQ, Morris PJ (2011) Do wound complications or lymphoceles occur more often in solid organ transplant recipients on mTOR inhibitors? A systematic review of randomized controlled trials. Transpl Int 24: 1216-1230.

17. 17. Marcén R (2009) Immunosuppressive drugs in kidney transplantation: impact on patient survival, and incidence of cardiovascular disease, malignancy and infection. Drugs 69: 2227-2243.

18. Miles CD, Skorupa JY, Sandoz JP, Rigley TH, Nielsen KJ, et al. (2011) Albuminuria after renal transplantation: maintenance with sirolimus/low-dose tacrolimus vs. mycophenolate mofetil/high-dose tacrolimus. Clin Transplant 25: 898-904.

19. DiMatteo MR, Giordani PJ, Lepper HS, Croghan TW (2002) Patient adherence and medical treatment outcomes: a meta-analysis. Med Care 40: 794-811.
20. Garber MC, Nau DP, Erickson SR, Aikens JE, Lawrence JB (2004) The concordance of self-report with other measures of medication adherence: a summary of the literature. Med Care 42: 649-652.

21. Hamilton GA (2003) Measuring adherence in a hypertension clinical trial. Eur J Cardiovasc Nurs 2: 219-228.

22. Prado JC Jr, Kupek E, Mion D Jr (2007) Validity of four indirect methods to measure adherence in primary care hypertensives. J Hum Hypertens 21: 579584.

23. Prendergast MB, Gaston RS (2010) Optimizing medication adherence: an ongoing opportunity to improve outcomes after kidney transplantation. Clin J Am Soc Nephrol 5: 1305-1311.

24. Schmid-Mohler G, Thut MP, WÃ/4thrich RP, Denhaerynck K, De Geest S (2010) Non-adherence to immunosuppressive medication in renal transplant recipients within the scope of the Integrative Model of Behavioral Prediction: a cross-sectional study. Clin Transplant 24: 213-222.

25. Denhaerynck K, Dobbels F, Cleemput I, Desmyttere A, SchÃafer-Keller P, et al. (2005) Prevalence, consequences, and determinants of nonadherence in adult renal transplant patients: a literature review. Transpl Int 18: 1121-1133.

26. Dew MA, DiMartini AF, De Vito Dabbs A, Myaskovsky L, Steel J, et al. (2007) Rates and risk factors for nonadherence to the medical regimen after adult solid organ transplantation. Transplantation 83: 858-873.

27. Weng FL, Israni AK, Joffe MM, Hoy T, Gaughan CA, et al. (2005) Race and electronically measured adherence to immunosuppressive medications after deceased donor renal transplantation. J Am Soc Nephrol 16: 1839-1848.

28. McEwan P, Dixon S, Baboolal K, Conway P, Currie CJ (2006) Evaluation of the cost effectiveness of sirolimus versus tacrolimus for immunosuppression following renal transplantation in the UK. Pharmacoeconomics 24: 67-79.

29. Muduma G, Shaw J, Hart WM, Odeyemi A, Odeyemi I (2014) Cost utility analysis of immunosuppressive regimens in adult renal transplant recipients in England and Wales. Patient Prefer Adherence 8: 1537-1546. 